\title{
Processos de aprendizagem das atividades de educação em saúde no cotidiano de trabalho dos Agentes Comunitários de Saúde
}

\author{
Learning processes of health education activities in the daily work of \\ Community Health Agents \\ Marcia Cavalcanti Raposo Lopes; Cristina Maria Toledo Massadar Morel ${ }^{1}$ \\ Fundação Oswaldo Cruz
}

\section{RESUMO:}

Este artigo analisa como os Agentes Comunitários de Saúde (ACS) desenvolvem suas atividades educativas e quais experiências estimulam processos de questionamento e aprimoramento destas atividades. Promove-se uma discussão sobre onde eles buscam referências para realizarem estas atividades; em que medida os serviços de saúde favorecem este processo e como aprendem, apreendem e aprimoram seu trabalho. Estas reflexões tomaram por base a análise de entrevistas dialogadas realizadas com nove ACS atuantes no estado do Rio de Janeiro há mais de dois anos. Observou-se como estes trabalhadores, mesmo sem as condições adequadas de trabalho, produzem sentidos para os eventos de seu dia a dia, se reinventando. Entretanto, identificou-se a importância de um espaço de formação para eles. Tal espaço pode ser enriquecedor e promover a construção de práticas educativas potentes para a transformação, não de hábitos, mas de sujeitos - trabalhadores e usuários - na luta por condições de saúde e vida melhores.

Palavras-chave: Educação em Saúde; Agente Comunitário de Saúde; Aprendizagem inventiva

\section{ABSTRACT:}

This paper analyses the how Community Health Agents (CHA) realize their educational activities and which sort of experiences stimulate a critical and improving processes of these activities. We discuss: how the CHA looking for references to support their activities; in which way health facilities contributes to the work processes; and how the CHA learn, embody and improve their work activities. We reflected about this paper questions based on nine dialogued interviews took from CHA with more than two years at the work field experience, in Rio de Janeiro State, Brazil. We observed that even though there was no ideal work environmental these CHA build meanings for their everyday events and recreate themselves. Additionally, we identify the importance of a training place for them. This place may be a primordial ground to enhance and promotes the construction of powerful educational practices able to change, not habits, but people workers and users of the health system - in the struggle for better life and health conditions.

Key-words: Health education; Community Health Agents; Inventive learning 


\section{Introdução}

As ações de educação em saúde são, hoje, uma das principais estratégias, não só para a construção da proposta oficial de participação social no SUS, mas também para a constituição de um sistema de saúde comprometido com a transformação das práticas sociais. Estas ações estão presentes formalmente na Política Nacional de Atenção Básica e no desenho das atribuições de todos os profissionais da Estratégia Saúde da Família e, especialmente, dos Agentes Comunitários de Saúde (ACS). Elas são entendidas como fundamentais para o trabalho de promoção da saúde a ser realizado pelas unidades de Saúde da Família.

Percebe-se, entretanto, que não se prevê, e quase nunca se oferece, qualquer formação para os trabalhadores desenvolverem estas atividades. Se tomamos o caso do ACS, é preciso ainda salientar que estes trabalhadores, muitas vezes, antes de começarem a exercer suas atividades rotineiras, passam apenas por uma formação introdutória, que pouco discute o seu trabalho cotidiano no serviço de saúde. Estes profissionais, em geral, têm uma formação assistemática e incipiente. Além disso, como nos mostram Rosseto e Silva (2010), a partir de um estudo no sul do Brasil que possivelmente também espelha outras realidades de nosso país, a educação permanente ofertada é extremamente tecnicista. Neste sentido, abre-se pouco espaço para a problematização dos modos de fazer educação em saúde.

Nossa experiência na formação de ACS, como docentes do Curso Técnico de Agentes Comunitários de Saúde (CTACS) da Escola Politécnica de Saúde Joaquim Venâncio/Fiocruz, tem nos mostrado, também, como os alunos têm poucas oportunidades para problematizar suas atividades educativas. Temos sido desafiadas a cada semestre a pensar na nossa prática educativa junto a estes alunos no sentido de promover movimentos e experiências que impulsionem esta problematização e a mudança nas práticas educativas dos ACS.

Assim, este estudo teve por objetivo analisar a maneira como os ACS desenvolvem suas atividades educativas e quais experiências estimulam processos de questionamento e aprimoramento destas atividades. Procurou-se investigar onde estes trabalhadores buscam as referências para realizarem estas atividades; como os serviços de saúde favorecem este processo e como eles aprendem, apreendem e aprimoram o trabalho no seu cotidiano. 
É importante ressaltar que consideramos, com Kastrup (2010), que é possível mobilizar diferentes experiências de aprendizagem. Segundo esta autora, a cognição pode se constituir a partir da recognição ou da invenção. Os dois processos ocuparão lugares distintos, mas complementares. O primeiro, a que estamos mais habituados e que é largamente tematizado pela psicologia, se atém à apreensão de informações e resolução de problemas. Se investimos só nele, abrimos mão da potência de transformação dos processos cognitivos e do mundo à sua volta. $\mathrm{O}$ segundo se caracteriza por seu aspecto inventivo e enfatiza a possibilidade do sujeito de inventar a si e ao mundo.

Como escrevem Sordi e De-Nardin (2009: 73):

De um lado, temos as experiências de recognição que permeiam nosso cotidiano e nos permitem o reconhecimento dos objetos e de operações entre os mesmos de modo que possamos ter um bom desempenho diante das situações com as quais nos deparamos. São elas que nos dão condições de solucionarmos nossos problemas mais imediatos. Por outro lado, a cognição não se esgota na repetição e na solução do problema, mas se potencializa na capacidade humana de problematizar e na sua atividade inventiva que elimina o determinismo do objeto ou do ambiente.

Dessa forma, o entendimento da cognição não fica limitado a interpretar um mundo pré-estabelecido. Para esta abordagem da cognição, "não há efetivamente mundo dado nem sistema cognitivo preexistente. Ambos são co-engendrados, de modo recíproco, através da ação" (SANCOVSCHI; KASTRUP, 2008: 170).

Kastrup (2001) aponta como o processo de aprendizagem inventiva se dará no plano da produção da subjetividade. Ele não acontece a partir de uma relação entre um sujeito previamente constituído e um mundo composto de objetos.

Ao contrário, faz-se num encontro de diferenças, num plano de diferenciação mútua, em que tem lugar a invenção de si e do mundo. Sujeito e objeto são efeitos, e não pontos de partida ou pólos pré-existentes, pois o signo se expressa numa matéria, mas não é objetivo; afeta o sujeito, mas não é subjetivo. Sem ser objeto de recognição, força o movimento da subjetividade (KASTRUP, 2001: 20).

O termo "signo" empregado pela autora, no sentido deleuziano, não é apenas linguístico, mas está presente em objetos, matérias, pessoas. A aprendizagem se dá então pelo deciframento destes signos emitidos em diferentes domínios; por exemplo, o aprendizado, por uma cozinheira, dos odores e texturas dos ingredientes da comida (KASTRUP, 2001). Nesta perspectiva, no decorrer da aprendizagem, o encontro com os signos, que é o encontro com a diferença, produz constantes transformações em quem aprende. 
Neste sentido, a autora critica a visão de aprendizagem apenas como a passagem entre não saber e saber: "É certo que a aprendizagem conduz a um saber, mas este é singular, diferencial e provisório, não gera a ilusão de uma lei transcendente e universal. A aprendizagem não cessa com o saber, não obstaculiza a continuidade do processo de diferenciação de si mesmo" (KASTRUP, 2007: 225).

A partir da ideia de uma circularidade inventiva, em que há constantes reinvenções, a aprendizagem é compreendida como a cognição em movimento. Tendo em vista este movimento de circularidade, esta se desenvolve em torno do contato com a novidade, que perturba, produzindo rupturas e transformações em quem aprende, e ao mesmo tempo envolvendo mecanismos de sedimentação de conhecimentos.

Portanto, a aprendizagem não se dá apenas a partir de encontros fortuitos, ela exige também disciplina no lidar com os desafios. Não se trata somente de se deixar levar pelo acaso, pelos movimentos espontâneos, pois é preciso, por meio da repetição, da experiência, proceder ao cultivo. Em relação a este aspecto, Kastrup (2008) vai se referir aos estudos de Varela et alii (2003). A partir da perspectiva destes autores, aprendizagem não se restringe a uma atividade intelectual, e implica na produção de uma relação do corpo com o mundo. Desenvolvem então a ideia de corporificação do conhecimento: “A cognição não é a representação de um mundo preconcebido por uma mente preconcebida, ao contrário, é atuação de um mundo e uma mente com base em uma história de diversidade de ações desempenhadas por um ser no mundo. Compreende-se então a cognição como ação incorporada". (VARELA et alii., 2003: 26).

Vale dizer que alguns autores da psicologia do trabalho francesa, como Clot e Dejours, se aproximam dessas ideias, mesmo que por outro viés, quando discutem a construção, pelo trabalhador, de um saber sobre seu ofício.

É a partir destas discussões que buscamos olhar o desenvolvimento e processo de aprendizagem e construção de saber do ACS sobre suas atividades de educação em saúde.

\section{Metodologia}

Para buscar nos aproximar da maneira como os ACS aprendem e aprimoram suas atividades de educação em saúde, nos propusemos a conversar com os agentes sobre seu trabalho educativo e a transformação que ele foi sofrendo ao longo de suas experiências formativas e laborativas. Assim, foram realizadas entrevistas dialogadas com nove 
Agentes Comunitários de Saúde, visando aproximação à maneira como foram construindo seus saberes e suas práticas de educação e saúde e reinventando a si mesmos.

$\mathrm{O}$ encontro com os participantes da pesquisa foi facilitado pelo fato de atuarmos como docentes em um curso técnico de agentes comunitários de saúde no Rio de Janeiro. Assim, pudemos fazer contato com ACS que eram alunos do curso, ex-alunos, ou que foram indicados por estes. Do grupo de entrevistados, todos atuavam no município do Rio de Janeiro, com exceção de um deles, que atuava no município de Duque de Caxias. Dos nove ACS, oito eram mulheres. Todos os agentes entrevistados exerciam esta função há pelo menos dois anos.

As entrevistas se constituíram em conversas estimuladas por um roteiro, mas que não se prenderam a ele. Pelo contrário, tiveram como proposta explorar, construir e analisar com os agentes como constituíram suas experiências de formação e trabalho no que diz respeito às atividades educativas. Trata-se, portanto, não de uma coleta de informações, mas de um processo de co-construção, com os sujeitos, de seu percurso de desenvolvimento no trabalho. Nessa perspectiva, buscamos problematizar o que é lembrado e reconstruído por cada um como passos, atalhos, desvios - enfim, movimentos importantes.

As entrevistas foram realizadas em espaço não institucional que melhor convinha aos entrevistados. Todos eles foram esclarecidos sobre a pesquisa, participaram voluntariamente das entrevistas e assinaram o TCLE. A pesquisa recebeu aprovação do Comitê de Ética em Pesquisa da Escola Politécnica de Saúde Joaquim Venâncio/Fiocruz (Parecer número 1.646.953)

Buscou-se, a partir destas entrevistas, problematizar o processo de aprendizagem dos ACS, seja no trabalho, seja em espaços formativos, considerando suas experiências de vida, no trabalho e, quando fosse o caso, na escola. Parte desta problematização foi coconstruída pelos próprios ACS.

A partir da leitura das transcrições das entrevistas, foram definidas categorias para análise. Separar estas categorias nos facilitou, em alguma medida, construir uma problematização sobre falas dos agentes; no entanto, elas não podem ser entendidas de forma estanque. Compreendemos que elas estão imbricadas umas nas outras.

A primeira categoria diz respeito às experiências e às referências que os ACS buscam para construir seu trabalho educativo; a segunda categoria procura analisar as relações da formação e do processo de trabalho com a aprendizagem do trabalho e a 
terceira categoria diz respeito a como estes trabalhadores problematizam e modificam suas atividades de educação em saúde e a si mesmos.

\section{Como os ACS constroem sua atuação como educadores em saúde}

Ao se abrir espaço para os ACS abordarem sua atuação no campo da educação em saúde, praticamente todos falaram longamente. Descrevem diferentes atividades e estratégias que utilizam no seu cotidiano, seja no serviço, seja na comunidade.

É possível perceber que os agentes entendem o trabalho de educação em saúde de forma bastante ampla. O dia a dia nos serviços de saúde parece possibilitar a expansão de uma concepção que aparece, muitas vezes, para leigos, como ligada apenas a campanhas e orientações sanitárias. Dessa forma, vemos os ACS abordarem diferentes trabalhos com os usuários que vão desde conversas informais para explicações em relação às prescrições médicas, até coordenação de grupos de artesanato e apoio a idosos solitários, passando pela mobilização da comunidade para luta por melhores condições de vida e saúde.

Neste enorme espectro de ações, aparecem diversas preocupações que costumam orientar a maneira como constroem suas atividades. Evidentemente, estas preocupações estão relacionadas com seus valores e experiências de vida e, também, é claro, com suas vivências no trabalho. Entre os pontos em que os ACS mais se estenderam em sua explanação sobre suas atividades está a construção de uma relação com o usuário. $\mathrm{O}$ vínculo é abordado, de maneira geral, como o grande facilitador das ações educativas, sendo ele existente antes do trabalho ou tendo sido construído através do trabalho.

"Não tive dificuldade de fazer as visitas não, com o tempo você vai conhecendo as famílias, vai se entrosando melhor e o trabalho fica mais fácil” (ent.8).

"Mas tem uma vantagem, eu já conhecia essas pessoas. Então eu já sei uma forma de iniciar o assunto, falar, acaba não sendo um papo muito formal pra não ter que ser muito maçante [...]. Eu procuro ser bem informal. Até pelo conhecimento mesmo. Eu começo a falar sobre qualquer assunto e acaba rolando a questão da saúde” (ent. 5).

"Então acho que isso fez muita diferença, da gente aprender no dia a dia a forma como as pessoas chegam pra gente, no olhar diferenciado de perceber quando a 
pessoa está te falando alguma coisa que quer uma ajuda, não necessariamente uma ajuda pra medicação, às vezes é só uma conversa" (ent.5).

O fato de o ACS ser morador da comunidade propicia a construção de uma relação diferente com as pessoas do lugar e também possibilita que ele se coloque mais próximo delas.

“...como eu sou moradora, nascida e criada na comunidade, eu conheço as pessoas, já conhecia todo mundo, e a maioria daquelas pessoas me viram nascer, também vi os filhos delas, essas coisas assim, então a gente falava: "vamos melhorar nossa comunidade, a gente está tentando fazer um trabalho"” (ent.9).

"Eu costumo dizer que eu me ponho no lugar do paciente, estou desse lado de cá como profissional, mas eu poderia estar do lado dele, e eu queria ser ouvida, eu queria ser entendida naquilo, entendeu? É mais ou menos isso, mas é uma caminhada que a gente aprende" (ent.9).

Ao discorrerem mais detalhadamente sobre suas atividades de educação em saúde, seja nas visitas domiciliares, seja nos grupos educativos que desenvolvem, os ACS se preocupam muito em citar os diferentes temas abordados (como por exemplo, hipertensão, diabetes, pediculose, amamentação). É possível perceber que eles se empenham em tentar adequá-los às necessidades da população, embora ainda permaneçam muito associados aos agravos selecionados pelo Ministério da Saúde. Apenas dois entrevistados, ambos ligados a movimentos sociais, comentaram sobre temas que se afastavam de conteúdos relativos à prevenção e cuidado com doenças. Dessa forma, assuntos mais relacionados com o conceito de saúde ampliado (como lixo, saneamento etc..) são muito pouco abordados pelos trabalhadores entrevistados.

“Toda quarta-feira nós temos esse grupo, [...] muitos vão porque gostam de participar, para educarmos na alimentação, na atividade física, para melhorarem a qualidade de vida deles, e isso faz com que a diabete controle, a hipertensão dê uma controlada e eles começam a pensar melhor, até aceitar essas enfermidades que eles têm, que precisa aprender a conviver com elas, que aí se torna uma maneira melhor de administrar, de se cuidar. Eu acho que isso é uma educação. 
E aí nós falamos do pé diabético, a gente fala de alimentação, fala de várias coisas, cortar unha, cuidar da pele, higiene bucal, tudo isso. Eu acho que é uma educação" (ent.9).

Durante as entrevistas, muitas vezes, também abordaram a forma como costumam apresentar estes temas, embora de maneira pouco sistematizada. Seus objetivos, quase sempre, referem-se à transmissão de informações, com a expectativa de que os usuários assumam para si um estilo de vida saudável, como prescrevem os serviços de saúde. Há pouca menção a debates sobre os determinantes sociais da saúde ou mobilização para ações de transformação das condições de vida e saúde da população, embora haja preocupação com a realidade social dos usuários.

“O importante é você deixar ele falar primeiro. Deixa eles começarem a falar, e você entra no mundo deles, falar de educação em saúde no mundo deles, da linguagem deles, da forma deles, eles atendem melhor e eles vão aceitar melhor o conselho que você vai dar, aquela dica que você vai dar, eles aceitam melhor. [...] Porque é muito ruim você impor, impor pro diabético que ele não tem que comer isso, que ele não pode fazer isso, não pode fazer aquilo" (ent.7).

Tomando por base estas análises, percebe-se como os ACS buscam desenvolver seu trabalho a partir de suas vivências na comunidade e da proximidade que constroem com seus usuários. Ao mesmo tempo, tomam como referência as diretrizes dos serviços de saúde, ainda muito prescritivas e biomédicas.

Como apontado por Bornstein et alii. (2014):

Esse profissional transita entre saberes distintos, o popular e o científico, o que confere potência a seu trabalho e implica no desafio de conciliar posições diversas: adquiriu um saber técnico, que lhe dá um status profissional, $e$, simultaneamente, tem acesso aos saberes advindos da classe popular, a qual pertence. Ao mesmo tempo que tem como suporte um saber valorizado socialmente, deve preservar o saber popular, que seria sua marca (BORNSTEIN et alii., 2014: 1327).

Dessa forma, vemos presente na fala dos agentes tanto uma grande preocupação com a relação e a escuta dos usuários, com a realidade em que estes vivem, quanto um "desejo" disciplinador em relação a seus hábitos de vida cotidianos a partir da lógica prevencionista das equipes da ESF. De maneira geral, levam em consideração as condições de vida dos usuários e estabelecem um canal de comunicação com estes. Entretanto, os agentes acabam materializando as propostas das políticas de saúde, quase 
sempre verticais, e se aproximam muito do que comumente se classifica como concepção tradicional de educação. Muitas vezes, inclusive, é possível ver em suas falas as contradições que o encontro entre esses valores e essas formas de atuar acabam produzindo em seu cotidiano de trabalho.

Vale ressaltar, em especial, que o conhecimento de quem está imerso nas mesmas condições precárias de vida dos usuários dá legitimidade ao saber construído na prática e favorece o desenvolvimento das ações dos ACS.

"Porque uma coisa é você trabalhar filosoficamente com a miséria, a miséria como produto, outra coisa é você vivenciar diariamente o caos, vivenciar diariamente a miséria. E isso, nenhum curso vai te preparar, ter empatia não se aprende na universidade, é uma experiência de vida anterior" (ent.2).

“A gente vai acompanhar aquela pessoa. O médico, por mais que ele também acompanhe, é dentro de um consultório. Então eu acho que essa formação tem esse abismo ali no meio, que eu estou ali no lugar, eu estou enxergando o todo, aquela pessoa naquela casa, naquela família, toda a conjuntura" (ent.1).

Como já ressaltado, o diálogo e a proximidade com os usuários são relatados por muitos como elemento fundamental para terem desenvolvido outros olhares e maneiras de realizar suas atividades educativas. E neste sentido, eles se aproximam também das concepções educativas mais dialógicas: preocupam-se em adaptar a linguagem a quem vai escutá-los, ajudando o usuário a se organizar para poder seguir as orientações médicas (por exemplo, fazendo desenhos relativos à hora do dia em que os remédios devem ser tomados), evitam expor os usuários na frente de outras pessoas, pensam em atividades menos normativas e que proporcionem convivência, escutam o usuário e tentam entrar no mundo dele para poder fazer o trabalho de educação em saúde, conversam individualmente durante a visita domiciliar para que o usuário possa ser mais ouvido.

\section{Formação, processo de trabalho e desenvolvimento das práticas de educação em saúde}

Parece claro em nossas discussões anteriores que o cotidiano no interior dos serviços de saúde tem forte influência na forma como os ACS desenvolvem suas práticas educativas. Entretanto, é possível perceber também que o dia a dia de trabalho oferece 
muito pouco espaço para os ACS refletirem e aprimorarem suas práticas de educação em saúde. A formação ofertada é bastante pontual e precária. O tema de educação em saúde é pouco abordado e, quase sempre, só voltado para conteúdos sobre doenças que devem ser repassados aos usuários. As discussões sobre educação e participação social parecem não estar muito presentes, seja na formação inicial (quando esta acontece), seja nos processos de educação permanente.

"Agora, como abordar o paciente, como entrar na casa, como sai daquela casa, nada disso nunca foi dito, nunca foi ensinado. Até hoje, as pessoas que entram é a mesma maneira, as pessoas entram sem nenhuma orientação, não tem uma qualificação, não tem uma capacitação, quem entra hoje ou quem entrou há oito anos atrás, e creio quem entrou há 15 anos atrás aqui, foi o mesmo tipo de colocação, colocou e vai” (ent.4).

Os ACS também colocam que o processo de trabalho atual não favorece as atividades de educação em saúde. Ao discorrerem sobre suas ações nesta área, os entrevistados falam constantemente sobre como a forma de organização do serviço afeta suas ações. O excesso de trabalho e a desvalorização destas atividades no cotidiano dos ACS dificultam por si só sua realização, e mais ainda, que estas sejam planejadas, avaliadas e repensadas. Em geral, a busca incessante das metas, abordada principalmente pelos ACS do município do Rio de Janeiro, não favorece processos de discussão ou reflexão sobre o trabalho. As trocas entre profissionais de saúde e as reuniões de equipe praticamente não aparecem, nas entrevistas, como espaços de aprimoramento de suas atividades.

Em relação aos ACS do município do Rio de Janeiro, antes mesmo da proposta da Política Nacional de Atenção Básica (PNAB) 2017 que precarizou ainda mais este trabalhador, Fonseca e Mendonça (2015) já nos mostravam que o processo de trabalho destes profissionais era marcado pela parcelarização e simplificação. Este não favorecia, portanto, o desenvolvimento deste trabalhador: "A análise do trabalho dos ACS a partir do estudo de campo possibilitou construir significados sobre as características que este trabalho tem adquirido, como a combinação entre parcelamento de atividades e simplificação do trabalho. Assim, atribuições que teriam uma dimensão mais complexa 
no marco da educação em saúde são convertidas em tarefas fortemente marcadas por uma perspectiva utilitarista" (FONSECA ; MENDONÇA, 2015: 53).

Vale destacar que alguns entrevistados que chegaram a trabalhar no Programa de Agentes Comunitários de Saúde (PACS) ${ }^{2}$ citam com saudades este momento e resgatam outras formas de organização de seu trabalho que favoreceram o desenvolvimento de suas atividades educativas. Uma das ACS comenta sobre o acompanhamento que a enfermeira fazia de seu trabalho, compreendendo as conversas com essa última após cada visita como uma fonte importante de seu aprendizado.

"Quando a gente fazia alguma coisa que eles achavam que a gente não estava orientando direito ou que a gente esqueceu de orientar ou que a gente podia ter orientado, elas falavam: 'da próxima vez você orienta dessa forma, você fala isso e isso', ou 'você faz isso'. [...] às vezes, a gente tinha alguma dúvida de como fazer o remédio, a gente perguntava a elas; como a gente pode orientar a pessoa que não enxergava direito, aí a gente procurava ajuda de um vizinho, alguma coisa assim" (ent.5).

O grau de organização do serviço para acompanhamento do trabalho dos ACS e o grau de autonomia dos mesmos aparecem como pontos importantes para a realização do trabalho educativo. É a mesma entrevistada que teve um trecho da fala destacado acima que observa que, com o tempo, houve também a possibilidade de ter maior participação nas atividades:

“[...] o agente de saúde pode fazer um grupo sozinho, antigamente, não, o agente de saúde só fazia parte como se fosse a cadeira daquele grupo, é uma cadeira que está ali, já botou a cadeira no lugar, então pode sentar e ficar ali, acabou. Era como se fosse só mais um ouvinte daquela palestra ou daquele grupo. Agora o agente de saúde participa, mesmo que não seja ele organizando aquele grupo, mas se ele quiser participar, ele vai poder dizer o que ele quiser dizer. Antes a gente não tinha voz, agora tem" (ent.3).

Ainda em relação aos processos de trabalho, a troca de experiência entre os ACS, mesmo realizada de forma não sistematizada, também aparece em uma entrevista como um elemento que contribui para a aprendizagem: 
"E a gente sempre teve esse hábito daquela sala ser o lugar da gente partilhar, então a gente vai pra lá, chora, come, conversa, briga, é um lugar como se fosse um lugar sagrado pra gente. E hoje a gente parou lá pra conversar, porque não tinha computador funcionando, a gente parou um pouquinho, e foi uma coisa tão bacana que a gente conseguiu, paramos pra discutir a criminalização das drogas” (ent.1).

Vale dizer que a aprendizagem a partir do coletivo aparece também em uma entrevista, mas a partir de uma experiência pontual e muito específica da entrevistada:

“A ida à Brasília [em função de uma chamada do sindicato para um movimento político], a troca de experiência com outros profissionais de outros estados, a conversa com outros profissionais de diferentes municípios daqui do Rio de Janeiro foi o start. A partir dessa ida à Brasília que nós construímos a semana do ACS que nós começamos a compreender um pouco da natureza do nosso trabalho e começamos a olhar pra essa vertente que educador popular de saúde, saindo pura e simplesmente do campo da mobilização política pela mobilização política, mas entendendo como parte do todo" (ent.2)

Apesar destas trocas serem mencionadas, é possível perceber como as aprendizagens no trabalho se dão, na maioria das vezes, de forma solitária, ou no máximo a partir de orientações de um colega. Pouco se fala sobre oportunidades para compartilhamento de descobertas e dificuldades no serviço.

\section{Aprendizagem e Subjetividade}

Retomando a discussão sobre aprendizagem apresentada no início deste artigo, ao analisarmos os relatos dos agentes, é possível perceber como a invenção e a recognição vão forjando os processos de aprendizagem e transformação das práticas destes trabalhadores. Tanto a incorporação de novas formas de ser e de se relacionar, quanto a busca e a assimilação de informações estão presentes em seus relatos. Muitas vezes imbricados, vemos como ambos os processos se constituem como importantes em seu dia 
a dia. Ainda que o primeiro processo - o da invenção - não apareça muito claramente para os entrevistados.

Quase todos os agentes entrevistados afirmaram que, a partir da experiência de trabalho, mudaram sua forma de realizar suas atividades educativas. Relataram que foram aprendendo e criando estratégias em seu cotidiano, apesar das condições pouco favoráveis à análise e ao desenvolvimento destas atividades. A maioria, entretanto, não chega a explicitar como aprendeu, e poucos conseguem relatar de forma mais sistematizada o processo de reflexão que resultou na transformação da prática. Identificam a mudança, mas não conseguem precisar como ela foi se dando. Estas constatações nos estimulam a refletir sobre as formas de aprendizagem destes adultos trabalhadores.

Percebemos claramente, como nos aponta Dejours (2004), que a habilidade e a sensibilidade técnica se capitalizam e se memorizam no corpo e se desenvolvem a partir do corpo. "O corpo inteiro - e não apenas o cérebro - constitui a sede da inteligência e da habilidade no trabalho" (DEJOURS, 2004: 29). Este fato torna difícil ao trabalhador descrever detalhadamente suas atividades.

O trabalhador hábil sabe, com frequência, como colocar em ação sua inteligência, embora nem sempre consiga se dar conta disto. Ele não dispõe de todas as palavras necessárias para descrever este trabalho efetivo e é até mesmo provável que o léxico, a própria língua, seja fundamentalmente deficitário em comparação com esta experiência do corpo (déficit semiótico) (Boutet, 1995). A inteligência está, por esta razão, sempre avançada em relação à consciência ou ao conhecimento que o próprio sujeito tem de si mesmo (DEJOURS, 2004: 30).

Mas podemos compreender também esta questão a partir de um outro ângulo, que não exclui o anterior. Muitos destes trabalhadores, pouco acostumados a lidar, no seu cotidiano, com formas de organização do pensamento próprias da escolarização, parecem ter mais dificuldade em avaliar e sistematizar suas experiências de trabalho a partir das questões que nós lhes apresentamos. Além disso, os encontros e descobertas; os movimentos e afetos que os fazem transformar-se transformando suas práticas são difíceis de serem percebidos. E são pouco valorizados pela concepção dominante de aprendizagem, tornando mais árdua sua percepção.

Quando estimulados a contar suas atividades cotidianas, entretanto, seu dia a dia de trabalho ganha cores vívidas. Percebe-se claramente como eles vão construindo caminhos possíveis para suas ações que permitam dar conta e produzir sentido para as exigências e constrangimentos do serviço. Ao mesmo tempo, respondem às diferentes 
demandas que vão se gerando a partir do estreitamento do contato com a vida dos usuários.

A noção de saber da experiência de Larrosa (2002), como aquele que "se adquire no modo como alguém vai respondendo ao que vai lhe acontecendo ao longo da vida e no modo como vamos dando sentido ao acontecer do que nos acontece" (Larrosa, 2002: 27), nos ajuda, neste ponto, a compreender os relatos dos agentes. Longe de afirmarem verdades sobre como devem ser feitas as abordagens de educação em saúde, os agentes deixam-se afetar pelos acontecimentos, pelos encontros com seus usuários e constroem suas abordagens a partir destas afecções.

Esta construção, como visto, se dá em condições precárias, na medida em que há fragilidade na formação e, também, processos de trabalho que pouco estimulam a realização e reflexão coletiva sobre as ações de educação em saúde. Ao mesmo tempo, é fácil perceber como o diálogo e a proximidade com os usuários são apontados como o elemento fundamental de seu trabalho e o motor do desenvolvimento de outros olhares e maneiras de realizar suas atividades educativas.

"é o dia a dia que você vai mudando, as atitudes dos próprios usuários fazem com que você mude o seu jeito de ser, às vezes você endurece mais, às vezes amolece mais, mas a própria atitude do usuário é uma caixinha de surpresa, cada dia você age de um jeito" (ent. 4).

Como abordamos anteriormente, a experiência e o cultivo são fundamentais para o aprendizado. Neste sentido, o conceito de corporificação do conhecimento, de Varela et alii.(2003), referido mais acima, nos auxilia a compreender os processos de aprendizagem expressos pelos ACS em seus relatos. Os autores demonstram que, em determinadas situações, mais do que solucionar problemas dados, o que deve ser valorizado nos processos cognitivos é a capacidade de podermos, a cada instante, a partir das nossas experiências, nos colocarmos questões significativas.

“Quando vou fazer a visita, eu estou lá pra qualquer coisa, eu espero qualquer coisa deles. Aprendi com o tempo que educação em saúde é improvisado, é um improviso, é na hora, é o assunto que surgir" (ent.7). 
Pode-se lidar com a imprevisibilidade, com "o assunto que surgir", quando, ao longo do tempo, por meio da aprendizagem pelo cultivo, há incorporação dos conhecimentos. Estes não são construídos apenas a partir de processos mentais, e envolvem todo o corpo.

No decorrer da atuação com os usuários, e também em outras situações de trabalho, vemos como a aprendizagem vai se dando por meio de uma circularidade inventiva, em que processos de sedimentação do conhecimento e de trato com a novidade vão se desenvolvendo de forma dinâmica. Há uma maneira singular de abordar o usuário, que exige um aprendizado sobre cada um deles e, evidentemente, uma transformação de si no processo.

Observa-se que o recurso da conversa como forma de interação com os usuários, mais do que as explanações mais típicas de grupos educativos, apareceram em muitas entrevistas:

"Eu prefiro sentar e conversar, estava sentindo que é por aí. É divertido porque as crianças falam com a gente, escrevem, começam a rir. Mas o interessante é ir na casa sem você saber o que te espera e você conversa" (ent.7).

“(...) nem sempre é só doença, às vezes é só uma conversa, a pessoa está se sentindo sozinha, não tem nada pra fazer, você chegou, a pessoa não deixa você sair de jeito nenhum. 'Que bom que você veio. Estava tão sozinha'” (ent.3).

"Eu sou assim: 'Você hoje está triste, o quê que está acontecendo? O que você tem? Sua glicose subiu'. Às vezes eles falam: 'não, meu problema...' Outro dia, um senhor [disse], 'meu filho está com problema nas drogas', aí eu já parei e fui conversar com ele aquele assunto. A gente consegue ver esse lado" (ent.9).

Os agentes percebem como a visita domiciliar, construída a partir de uma conversa, é uma oportunidade de estabelecer uma relação mais próxima com o usuário, e de aprender mais sobre suas necessidades. Tedesco et alii. (2013) observam que a conversa "funciona, não como uma conversação entre sujeitos pré-estabelecidos, mas como uma conversa, que procede por interseções, cruzamentos de linhas, agenciamentos coletivos de enunciação. [...] Questões aparentemente desconectadas com a conversa podem traçar linhas de vizinhança ou de indiscernibilidade. Uma conversa não é 
condicionada por especificidades, ela se faz nos encontros” (TEDESCO et alii., 2013, p.310).

Vemos como alguns dos ACS entrevistados demonstraram uma postura de abertura para o imprevisível, e, também, que, de alguma forma, estão atentos ao que se passa com eles e com os usuários no decorrer das conversas. Eles nos sinalizam que em sua atuação profissional há aprendizagem, há transformação de si mesmo, e, em alguma medida, há possibilidade de transformação de seus interlocutores.

Ao mesmo tempo, vemos como esta transformação vai também impulsionando a busca por informações e o investimento para assimilação de conteúdos técnicos importantes para sua atuação.

"A experiência muda realmente o olhar. Você, com o decorrer do tempo, acaba adquirindo um olhar diferente, vai buscando informações fora da instituição, vai buscando informação na prática e tentando moldar o seu trabalho, dar sentido ao seu trabalho" (ent.2).

Os ACS citaram, com frequência, que buscavam informações sobre temas relativos às doenças mais comuns no atendimento da ESF. Houve também muitos relatos de experimentações e busca de novas ideias em relação a recursos didáticos para seu trabalho como, por exemplo, álbuns seriados, jogos infantis, vídeos. Alguns relataram, ainda, investir na aprendizagem de saberes populares, buscando recursos terapêuticos alternativos para dar conta das necessidades de saúde dos usuários.

Dessa forma, além de desenvolverem a capacidade de se relacionar com os usuários, dialogando, e levando em conta sua condição social, os ACS vão ganhando também mais segurança, a partir do domínio de algumas informações técnicas, que buscam conseguir por meio da pesquisa por internet, ou ajuda de algum profissional de saúde, ex-professores e até usuários.

“...agora a gente se apropria mais das coisas, a gente sabe o que está dizendo e sabe aonde mostrar a pessoa pra procurar que aquilo que a gente está informando pra ela é verídico, você vai em tal lugar, você vê que a informação é a mesma, ou se você tiver dúvida, vai em tal lugar assim, ou procura na internet, agora tudo é internet, ou procura no telefone, liga pra alguém e tal, a gente informa 
com mais apropriação aquilo que está passando pra pessoa, tem mais segurança em dizer aquilo, porque tem mais coisas, a bagagem que você também carrega já pesa um pouquinho, aí fica mais fácil” (ent.3).

Esta busca por conhecimento não está separada dos conjuntos dos processos subjetivos e, como fala uma das entrevistadas, se dá a partir de um interesse em aprender: "Leituras, curiosidade, você vai ler. Você tem que ter vontade, porque não adianta você me falar: 'você quer ler sobre o álcool porque você tem que estudar sobre o álcool'. Não, a gente vai pegar os temas que vai tendo curiosidade" (ent.7).

Vemos se forjar aqui processos complexos de aprendizagem, onde mesmo a apreensão de informações se dá a partir dos movimentos subjetivos, nos apontando como os processos formativos precisam escapar de seu foco excessivo em conteúdos prontos para serem consumidos e aplicados pelos trabalhadores da saúde.

Como diz Gallo (2017), a partir de Deleuze: "Sendo o aprender um acontecimento, ele demanda presença, demanda que o aprendiz nele se coloque por inteiro. E exige relação com o outro. Entrar em contato, em sintonia com os signos é relacionar-se, deixar-se afetar por eles, na mesma medida em que os afeta e produz outras afecções" (GALLO, 2017: 110).

\section{Considerações finais}

O caminho percorrido neste estudo nos mostrou que é difícil construir um relato sistematizado sobre o aprender no cotidiano de trabalho. Percebemos que não foi simples para os agentes relatarem como foram aprendendo e aprimorando suas atividades educativas, seja a partir de sua experiência de trabalho, seja a partir de experiências formativas.

Ao analisar as entrevistas, a partir da concepção de aprendizagem apresentada por Kastrup, e também por Varela et alii., podemos considerar que o que foi aprendido e, consequentemente o como foi aprendido não necessariamente é percebido de maneira consciente, não sendo, portanto, facilmente explicitado por estes trabalhadores. Isto não significa, entretanto, que os ACS não tenham nos dado várias pistas de como o processo de transformação das suas práticas ocorre. 
Identificou-se que o vínculo construído com os usuários - seja este anterior ao início do trabalho como ACS, seja a partir deste trabalho - e o conhecimento sobre sua realidade social são pontos chave para o desenvolvimento das suas ações de educação em saúde. É possível perceber claramente, em seus relatos, como quase todos identificam mudanças não só em sua atuação, mas na forma de ver e se relacionar com os usuários e os problemas da comunidade. Vemos, também, como no cotidiano vão construindo formas de lidar com as contradições, quase sempre não percebidas por eles, entre a sabedoria construída na lida com os usuários, e os conhecimentos e regras de estilo de vida saudáveis presentes nas práticas cotidianas das unidades de saúde.

Podemos observar como eles são continuamente afetados pelos acontecimentos do dia a dia e, deixando-se afetar por eles, problematizam as situações, agindo sobre elas, transformando-as e se transformando no processo. Para tanto, se tornam sensíveis aos signos próprios do mundo de seus usuários, capazes de perceber seus humores, suas dificuldades, suas necessidades de saúde a cada momento. É esta sensibilidade que os ajuda a se moverem, a construir estratégias e até a construir processos próprios da recognição, ao buscarem e assimilarem conteúdos biomédicos importantes para sua atuação. Dessa forma, vão construindo um repertório de conhecimentos que lhes permite segurança para lidar com uma variedade de situações - muitas delas não previstas - que lhes são apresentadas.

De maneira geral, nas falas dos ACS, o trabalho pouco aparece como um espaço que favoreça, de forma sistematizada e coletiva, a troca de experiências e o aprimoramento de sua atuação educativa. Os diálogos entre os profissionais são identificados pelos entrevistados como oportunidade de aprendizagem, mas ocorrem de maneira pontual, dependendo da iniciativa de cada um, ou de pequenos grupos.

Mesmo sem as condições adequadas de trabalho ou grandes estímulos por parte dos serviços onde atuam, esses agentes produzem sentidos para os eventos de seu dia a dia e se reinventam em seu trabalho. Produzem com os usuários diferentes formas de desenvolver as atividades educativas, ainda que não se remetam a autores ou estudos referentes à educação em saúde e que a maior parte deles tenha dificuldades em sistematizar críticas aos processos naturalizados de seus espaços laborais.

Reconhecer e valorizar este aprendizado não significa, entretanto, não apontar para a importância de um espaço de formação para estes trabalhadores. Ao contrário, percebemos como tal espaço pode ser enriquecedor e produzir frutos para a construção 
de práticas educativas potentes para a transformação, não de hábitos, mas de sujeitos trabalhadores e usuários - na luta por condições de saúde e vida melhores.

Estas análises nos ajudam a pensar a construção desta formação, valorizando não só a capacidade de autonomia e busca de conhecimentos científicos necessários para a profissão, mas também o refinamento da sensibilidade para os signos, imprescindível para a construção deste trabalho. Como pontos importantes para estes dois processos, consideramos que os encontros, seja com livros, seja com pessoas com experiências e valores diferentes, seja com movimentos culturais e artísticos são fundamentais. Eles possibilitam produzir os estranhamentos necessários para desacomodar as práticas que ficam naturalizadas no cotidiano de trabalho no território.

\section{Referências}

BORNSTEIN, Vera Joana; MOREL, Cristina Massadar; PEREIRA, Ingrid D'avilla Freire e LOPES, Marcia Raposo. Desafios e perspectivas da Educação Popular em Saúde na constituição da práxis do Agente Comunitário de Saúde. Interface (Botucatu), Botucatu , v. 18, supl. 2, 2014, p. 1327-1339. Disponível em: <http://www.scielo.br/scielo.php?script=sci_arttext\&pid=S14143283201400060 $1327 \& \operatorname{lng}=\mathrm{en} \& n r m=\mathrm{iso}>$. Acesso em 05 ago 2020.

DEJOURS, Christophe. Subjetividade, trabalho e ação. Produção (online), São Paulo v. 14, n. 3, Dec. 2004, p. 27-34. Disponível em: $<$ http://www.scielo.br/scielo.php?script=sci_arttext\&pid=S010365132004000300004\&lng=en\&nrm=iso>. Acesso em: 05 Ago 2020.

FONSECA, Angélica Ferreira e MENDONÇA, Maria Helena Magalhães. Parcelarização e simplificação do trabalho do Agente Comunitário de Saúde. Revista Latinoamericana de Estudios del Trabajo, Rio de Janeiro, v. 20, n. 33, 2015, p. 29-57. Disponível em: https://www.arca.fiocruz.br/handle/icict/25376. Acesso em 05 ago 2020.

GALLO, Silvio. O Aprender em Múltiplas Dimensões. Perspectivas da Educação Matemática, v. 10, n. 22, 2017, p. 103-114. Disponível em: https://periodicos.ufms.br/index.php/pedmat/article/view/3491/3096. Acesso em: 04 nov. 2020.

KASTRUP, Virgínia. O funcionamento da atenção no trabalho do cartógrafo. Em: PASSOS, Eduardo; KASTRUP, Virgínia; ESCÓSSIA, Liliana da (orgs.) Pistas do método da cartografia: pesquisa-intervenção e produção de subjetividade. Porto Alegre: Sulina, 2010, p.32-51.

O lado de dentro da experiência: atenção a si mesmo e produção de subjetividade numa oficina de cerâmica para pessoas com deficiência visual adquirida. Psicologia ciência e profissão [online], v. 28, n. 1, 2008, p. 186-199. Disponível em: https://www.scielo.br/pdf/pcp/v28n1/v28n1a14.pdf. Acesso em: 04 nov. 2020.

- A invenção de si e do mundo: uma introdução do tempo e do coletivo no estudo da cognição. Belo Horizonte: Autêntica, 2007. 
. Aprendizagem, arte e invenção. Psicologia em Estudo, Maringá, v. 6, n. 1, 2001, p.17-27. Disponível em: https://www.scielo.br/pdf/pe/v6n1/v6n1a03.pdf. Acesso em 04 de nov. 2020.

LARROSA, Jorge. Notas sobre a experiência e o saber da experiência. Revista Brasileira de Educação [online]., n. 19, p. 20-28, 2002. Disponível em: https://www.scielo.br/pdf/rbedu/n19/n19a02.pdf. Acesso em: 04 de nov. 2020.

ROSSETO, Maíra e SILVA, Luiz Anildo Anacleto da. Ações de educação permanente desenvolvidas para os agentes comunitários de saúde. Cogitare Enfermagem. v. 15, n. $\quad 4, \quad 2010, \quad$ p. 723-729. Disponível: https://core.ac.uk/download/pdf/328056649.pdf. Acesso: 04 de nov. 2020.

SANCOVSCHI, Beatriz e KASTRUP, Virgínia. Algumas ressonâncias entre a abordagem enativa e a psicologia histórico-cultural. Fractal, Revista de Psicologia, v. 20, n. 1, 2008, p. 165-182. Disponível em: https://www.scielo.br/pdf/fractal/v20n1/a17v20n1.pdf. Acesso: 04 de nov. 2020.

SORDI, Regina e DE NARDIN, Maria Helena. Contribuições de Francisco Varela ao Estudo da Aprendizagem Inventiva em Sala de Aula. Informática na educação: teoria \& prática Porto Alegre, v.12, n.2, 2009, p. 82-92. Disponível: https://seer.ufrgs.br/InfEducTeoriaPratica/article/view/9918/7246. Acesso: 04 de nov. 2020.

TEDESCO, Silvia Helena; SADE, Christian e CALIMAN, Luciana Vieira. A entrevista na pesquisa cartográfica: a experiência do dizer. Fractal, Revista de Psicologia, v. 25, n. 2, 2013, p. 299-322.

VARELA, Francisco; THOMPSON, Evan e ROSCH, Eleanor. A mente incorporada: ciências cognitivas e experiência humana. Porto Alegre: Artmed, 2003.

Marcia Cavalcanti Raposo Lopes

Escola Politécnica de Saúde Joaquim Venâncio/Fiocruz

Email: marcia.lopes@fiocruz.br

Cristina Maria Toledo Massadar Morel

Escola Politécnica de Saúde Joaquim Venâncio/Fiocruz

Email: cristina.morel@ fiocruz.br

\footnotetext{
${ }^{1}$ Todos os autores colaboraram ao longo do processo, desde a elaboração até a revisão final do manuscrito. Os autores aprovaram o manuscrito final para publicação.

2 Programa que instituiu nacionalmente o trabalho do ACS e que buscava privilegiar uma concepção ampliada de saúde. Foi implementado 1991, pelo Ministério da Saúde inicialmente com o nome de Programa Nacional de Agentes de Saúde (PNACS). Um ano depois, o PNACS se transformou no Programa de Agentes de Saúde (PACS). Para entender melhor o histórico do trabalho do ACS, ver Silva e Dalmaso (2002).
} 